\title{
Studying the wettability of Si and eutectic Si-Zr alloy on carbon and silicon carbide by sessile drop experiments
}

$\underline{\text { Manoj Naikade }}^{1,2}$, Beate Fankhänel ${ }^{3}$, Ludger Weber ${ }^{2}$, Alberto Ortona ${ }^{4}$, Michael Stelter ${ }^{3}$, Thomas Graule $^{1,5}$

(1) Empa - Swiss Federal Laboratories for Materials Science and Technology, Dübendorf, Switzerland

(2) EPFL - Laboratory for Mechanical Metallurgy, École Polytechnique Fédérale de Lausanne, Lausanne, Switzerland

(3) Institute for Nonferrous Metallurgy and Purest Materials, TU Bergakademie Freiberg, Freiberg, Germany

(4) SUPSI - Scuola universitaria professionale della Svizzera italiana, Manno, Switzerland (5) Institute of Ceramic, Glass and Construction Materials, TU Bergakademie Freiberg, Freiberg, Germany

\begin{abstract}
The contact angles of two different systems, molten silicon and a eutectic Si-8 at. pct Zr alloy and their evolution over time on vitreous carbon and polycrystalline silicon carbide ( $\mathrm{SiC}$ ) substrates were investigated at $1500^{\circ} \mathrm{C}$ under vacuum, as well as in argon using the sessile drop technique. The contact angle and microstructure of the liquid droplet/solid substrate interface were studied to understand fundamental features of reactive wetting as it pertains to the infiltration process of silicon and silicon alloys into carbon or $\mathrm{C} / \mathrm{SiC}$ preforms. Both pure $\mathrm{Si}$ and the eutectic alloy showed good wettability on vitreous carbon and $\mathrm{SiC}$ characterized by equilibrium contact angles between $29^{\circ}$ and $39^{\circ}$. The eutectic alloy showed a higher initial contact angle and slower spreading as compared to that of pure Si. On vitreous carbon both silicon and the eutectic alloy formed $\mathrm{SiC}$ at the interface, while no reaction was observed on the SiC substrates.
\end{abstract}

\section{Introduction}

Silicon infiltrated silicon carbide ( $\mathrm{Si}-\mathrm{SiC}$ ) manufactured by means of the so-called liquid silicon infiltration process (LSI) has drawn considerable attention from different industrial sectors, due to the possibility of an industrial scale production of nearly net-shaped large complex components with very low porosity [1]. The first step in LSI consists of producing a carbon-based microporous medium known as a preform (which may already contain $\alpha$-SiC particles), which is easy to mold into the desired final shape. Later, in the furnace, the liquid silicon is pulled into the preform by capillary forces and reacts exothermally with the carbon preform to form a $\beta$-SiC body via reactive wetting and diffusion controlled conversion [2]. However, there are still some undesired aspects of LSI. Firstly, the presence of residual unreacted silicon in the composite impairs the mechanical properties above $1300^{\circ} \mathrm{C}$ [3]. Secondly, if carbon fibers are used as reinforcement, their reaction with silicon may result in the weakening of the composite [4, 5]. Finally, depending on the pore characteristics and the preform's reactivity, the solid phase reaction products could cause capillary 
obstruction and incomplete infiltration [6]. As a result of the diffusion of carbon through solid $\mathrm{SiC}$ being faster than that of silicon, the growth of the solid phase occurs into the capillary channel, therefore potentially obstructing liquid transport [7-9]. Additionally, the unreacted silicon expands during solidification and may create internal stresses and/or cracks.

One way of avoiding the unwanted reaction and obstruction of channels is to protect the reinforcement with an inert interphase, such as $\mathrm{SiC}$ or $\mathrm{BN}$. Although being effective, this technique is expensive in terms of equipment and process time. Furthermore, it fails to solve the problem of the limited operation temperature due to residual silicon. Another solution is to use metal - silicon alloys, as they have shown to reduce reactivity $[10,11]$ and lower the amount of residual silicon, as well as the infiltration temperature [12]. The alloying element must be chosen based on the liquid-phase equilibria and its ability to form refractory silicides, which have a higher melting temperature than pure silicon. This has been shown to be feasible for Si-Mo alloys infiltrated into carbon preforms $[13,14]$. Apart from increasing the melting point, the refractory silicides were found to improve mechanical properties and oxidation resistance at high temperatures [15]. Among most recent studies $[12,16]$, one example of refractory silicides used was $\mathrm{Si}-\mathrm{Zr}$ alloys. Si-Zr alloys have been used to infiltrate carbon preforms as to obtain a ceramic matrix composite (CMC) characterized by high strength, good oxidation resistance, and excellent ablation resistance. Several studies focussing on different aspects of metal-silicon alloy infiltrated CMCs can be found in literature [11-19], however, these works have mainly focussed on practical and applied aspects. More fundamental features of reactive wetting and capillary infiltration in reactive systems have been overlooked or not analysed in depth. Several groups have studied the wetting properties of silicon and silicon alloys on various types of graphite materials and $\mathrm{SiC}$ [20-33]. To our knowledge, there hasn't been any study yet featuring the fundamental wetting properties of any composition of $\mathrm{Si}-\mathrm{Zr}$ alloy on carbon or $\mathrm{SiC}$ substrates. The present work aims at filling this gap by performing classical sessile drop experiments to study the spreading of pure silicon and $\mathrm{Si}-\mathrm{Zr}$ alloy at $1500^{\circ} \mathrm{C}$ on vitreous carbon and polycrystalline $\mathrm{SiC}$ substrates and study the effect of reactive wetting.

\section{Experimental procedure}

The experiments were performed in an alumina tube furnace (Gero GmbH Neuhausen, Germany) under a controlled atmosphere. The furnace can be operated at a maximum temperature of $1600^{\circ} \mathrm{C}$, both under vacuum and an inert gas ( $\mathrm{Ar}$ or $\mathrm{N}_{2}$ ) atmosphere. The vitreous carbon (Sigma-Aldrich Chemie $\mathrm{GmbH}$, Germany) and polycrystalline $\mathrm{SiC}$ (3M Technical Ceramics, Germany) substrates measuring $15 \mathrm{~mm} \times 15 \mathrm{~mm}$ x $3 \mathrm{~mm}$ were manually polished using $\mathrm{SiC}$ paper with the following grit sizes: 800, 1200, 2000 and 4000. Next, semi-automatic polishing using $1 \mu \mathrm{m}$ diamond suspensions and final polishing with an acidic aluminum oxide suspension were performed. The surface roughness was measured by means of a NanoFocus $\mu$ surf explorer confocal microscope (NanoFocus AG, Germany) using $\mu$ Soft Analysis XT software. The pieces of pure silicon and Si8 at. pct $\mathrm{Zr}$ alloy (henceforth: $\mathrm{Si} 0.92 \mathrm{Zr} 0.08$ ) were carefully cleaned using a $\mathrm{HNO}_{3}(65 \%), \mathrm{HF}(40 \%)$ and $\mathrm{CH}_{3} \mathrm{COOH}(100 \%)$ solution in the ratio of 5:3:3, to remove the oxide layer, followed by rinsing 
with water then drying in a vacuum oven. The silicon and $\mathrm{Si}_{0.92} \mathrm{Zr}_{0.08}$ alloy pieces with the weight in the range of 50-80 mg were put on the substrates and placed into the alumina tube, as shown in Fig. 1. The small alumina tube, in which the samples were placed, was approximately half the length of the furnace, ensuring that the sample was near to the thermocouple situated in the middle of the furnace. The tube furnace had glass caps on both sides, while the light source and digital camera were placed on opposite sides. The image acquisition was carried out by means of a computerized digital image analyzer. The values of the height and the diameter of the droplets were taken directly from the images of the droplets during the experiments.

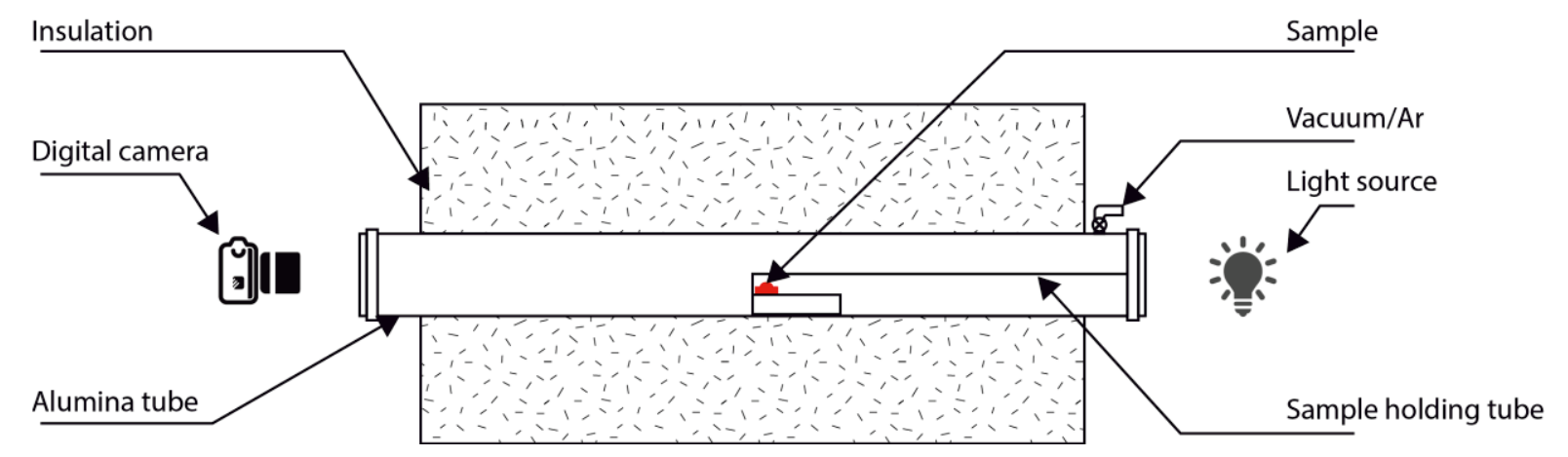

Fig. 1 Schematic of metal droplet on substrate placed in a tube furnace with both sides covered by glass to observe and measure the contact angle using a digital camera.

The contact angles of silicon and $\mathrm{Si}_{0.92} \mathrm{Zr}_{0.08}$ alloy on vitreous carbon and sintered silicon carbide (SiC) were determined at $1500^{\circ} \mathrm{C}$ for $1 \mathrm{~h}$. The measurements of the contact angles were started immediately after the formation of a liquid droplet after complete melting of the sample. For the calculations, it was assumed that the droplets took the form of a spherical cap, due to their tiny volume. The contact angles $\theta_{\text {cal }}$ were deduced from binary pictures using equation (1) where $h$ is the measured height and $d$ is the measured diameter of the droplet.

$$
\theta_{\text {cal }}=2 \arctan \frac{2 h}{d}
$$

The first set of experiments were performed under vacuum at $5 \times 10^{-5}$ mbar, using a turbomolecular pump (BOC Edwards, Munich, Germany), while the second set of experiments were performed under a static argon atmosphere (99.999\%, sourced from Linde) at 500-600 mbar. Furthermore, an Oxisorb ${ }^{\circledR}$ cartridge from Messer Group GmbH (Krefeld, Germany) was used before introducing the argon into the furnace, which should have provided a final purity of less than 5 ppb $\mathrm{O}_{2}$ within the argon. To ensure the cleanliness in the alumina tube, the furnace was repeatedly flushed with argon and pumped to high vacuum for at least 3 times before beginning the experiments. For the experiments carried out under vacuum, the furnace was heated to $1500^{\circ} \mathrm{C}$ with a heating rate of $350^{\circ} \mathrm{C} / \mathrm{h}$ and was held at $1500^{\circ} \mathrm{C}$ for $1 \mathrm{~h}$. For the experiments in argon, the furnace was heated to $1400^{\circ} \mathrm{C}$ with a rate of $350^{\circ} \mathrm{C} / \mathrm{h}$, later at $100^{\circ} \mathrm{C} / \mathrm{h}$ until reaching $1500^{\circ} \mathrm{C}$ and was held at $1500^{\circ} \mathrm{C}$ for $1 \mathrm{~h}$. Additionally, a few pieces of titanium sponge were placed near the 
substrate to act as an oxygen getter and reduce the oxygen partial pressure in furnace below the level caused by impurities in argon. The cross-sections of the solidified droplets and substrates were later studied using a SEM (Tescan VEGA3 SBU, EO Elektronen-Optik-Service GmbH, Germany) and EDX (BR AXS Quantax 200 EDX, Bruker Nano GmbH, Berlin, Germany) to analyze the morphology and composition of the reaction layer between the droplet and the substrate.

\section{Results}

\subsection{Surface roughness}

The surface roughness values determined in accordance with ISO 4287 for $\mathrm{R}_{\mathrm{a}}$ and ISO 25178 for $\mathrm{S}_{\mathrm{a}}$ values are summarized in Table 1.

Table 1 Surface roughness of substrates measured by NanoFocus confocal microscope using $\mu$ Soft Analysis XT software.

\begin{tabular}{l|cc} 
Substrate & $\mathrm{Ra}(\mathrm{nm})$ & $\mathrm{Sa}(\mu \mathrm{m})$ \\
\hline Vitreous carbon & $5.5-6.8$ & $0.04-0.07$ \\
$\mathrm{SiC}$ & $8.8-10.1$ & $0.10-0.17$
\end{tabular}

\subsection{Contact angles under vacuum}

The contact angles of pure silicon and the Sio.92 $\mathrm{Zr}_{0.08}$ alloy measured under vacuum at $5 \times 10^{-5}$ mbar on vitreous carbon and SiC substrates are shown in Fig. 2. The time on X-axis begins with the initial formation of the liquid droplet from a solid piece, as observed by the camera. The contact angle measured immediately after formation of the liquid droplet will be further referred to as the initial contact angle. The increase in pressure with increasing temperature is expected, however, it was observed that the pressure in the tube furnace kept rising with time, even though the temperature was constant at $1500^{\circ} \mathrm{C}$. Moreover, the height of the droplet kept reducing, whereas the diameter of the droplet remained unchanged. These two observations were interpreted as the vaporization of the droplet during the experiment, which apart from the initial contact angle, makes the measured contact angles incorrect. The accuracy of the contact angle measurement is estimated to be $\pm 2^{\circ}$. The estimation is based on the uncertainty of diameter and height measurement. The accuracy of the measurement was determined by repeating the calculation of one contact angle more than 20 times. The initial contact angle contact angles measured immediately after formation of the droplet are summarized in Table 2 for pure silicon with their respective melting temperatures. The $\mathrm{Si}_{0.92} \mathrm{Zr}_{0.08}$ alloy showed a slightly different behavior compared to pure $\mathrm{Si}$. The initial contact angle on vitreous carbon and $\mathrm{SiC}$ was $51^{\circ}$ and $52^{\circ}$, respectively, followed by slow spreading of the droplet for $120 \mathrm{~s}$ until it reached the final contact angle of $43^{\circ}$ and $44^{\circ}$ (Table 2 ). Since the spreading time is relatively short for the considerable effect of evaporation and change in diameter and height of droplet was clearly noticeable. The temperature change is also nominal for $120 \mathrm{~s}$. The measured contact angle at this time is referred to as the final contact angle after the droplet is formed. The equilibrium contact angle at $1500^{\circ} \mathrm{C}$ could not be measured due to the decrease in droplet height due to evaporation. 
Table 2 The initial and final contact angle of silicon and $\mathrm{Si}_{0.92} \mathrm{Zr}_{0.08}$ on vitreous carbon and $\mathrm{SiC}$ substrates and respective temperatures measured under vacuum.

\begin{tabular}{c|l|c|c|c}
\multirow{2}{*}{ Sample } & \multirow{2}{*}{ Substrate } & Melting temperature & \multicolumn{2}{|c}{ Contact angle $\left({ }^{\circ}\right)$} \\
\cline { 3 - 4 } & & $\left({ }^{\circ} \mathrm{C}\right)$ & Initial & Final \\
\hline \multirow{2}{*}{ Silicon } & Vitreous carbon & 1452 & 45 & - \\
& SiC & 1446 & 42 & - \\
\hline \multirow{2}{*}{$\mathrm{Si}_{0.92} \mathrm{Zr}_{0.08}$} & Vitreous carbon & 1404 & 51 & 43 \\
& $\mathrm{SiC}$ & 1399 & 52 & 44
\end{tabular}
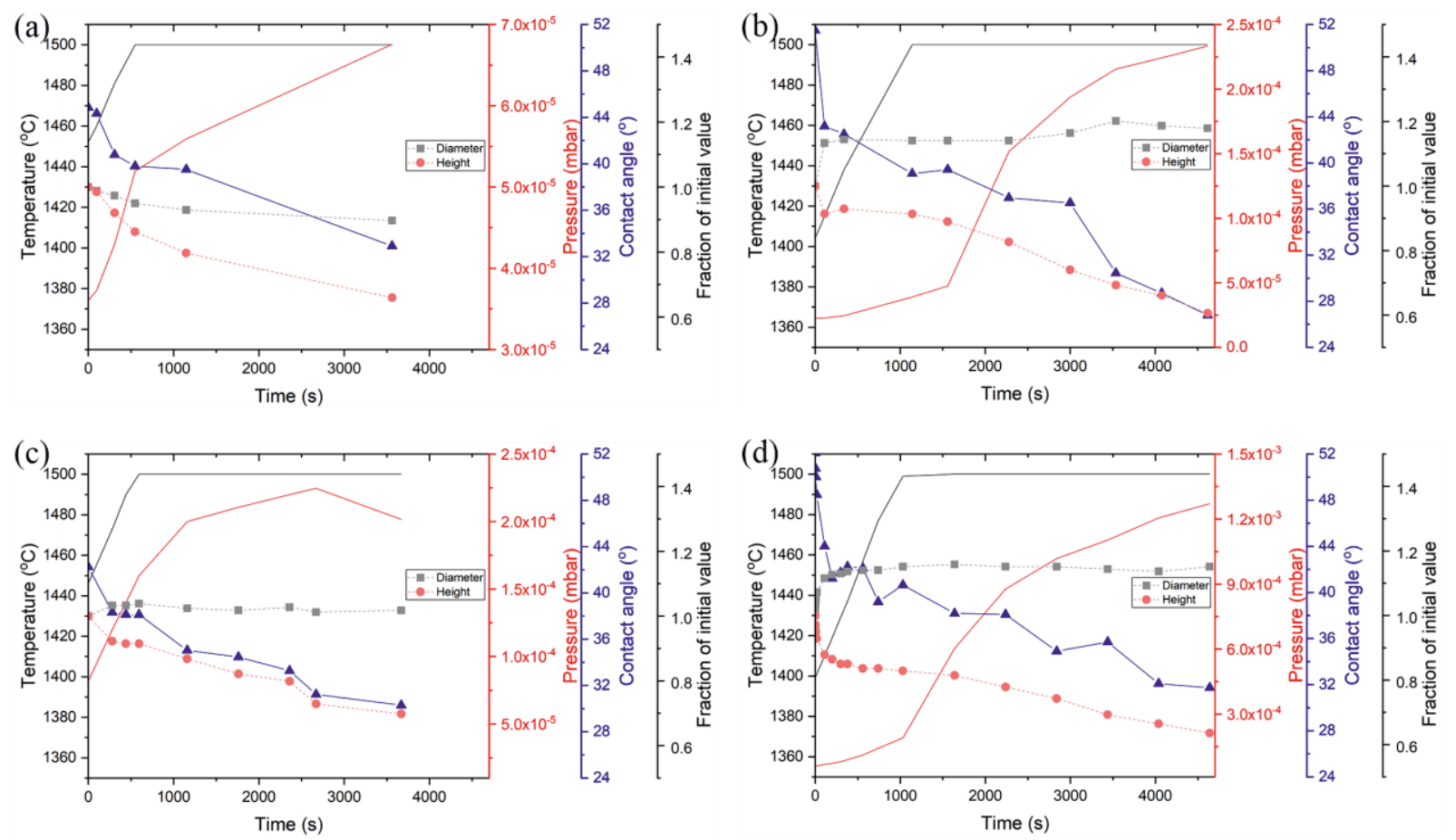

Fig. 2 Development of the contact angle, diameter and height of the droplet of (a) silicon on vitreous carbon (b) $\mathrm{Si}_{0.92} \mathrm{Zr}_{0.08}$ alloy on vitreous carbon (c) silicon on $\mathrm{SiC}$ (d) $\mathrm{Si}_{0.92} \mathrm{Zr}_{0.08}$ alloy on $\mathrm{SiC}$ with changing temperature and vacuum pressure.

\subsection{Contact angles under an argon atmosphere}

The contact angles of silicon and Si $0.92 Z_{0} 0.08$ alloy measured under and argon atmosphere at 500 mbar on vitreous carbon and SiC substrates are shown in Fig. 3. The partial pressure of Ar changed to $\sim 600$ mbar upon heating to $1500^{\circ} \mathrm{C}$ and raised further by $5-8 \mathrm{mbar}$ during the $1 \mathrm{~h}$ holding time at $1500^{\circ} \mathrm{C}$. The initial contact angle of silicon on vitreous carbon and $\mathrm{SiC}$ was $41^{\circ}$ and $42^{\circ}$, respectively which decreases within $60 \mathrm{~s}$ to the final contact angles of $35^{\circ}$ and $40^{\circ}$, respectively. The latter is not a significant decrease considering its still in the range of experimental accuracy. Once the temperature reached $1500^{\circ} \mathrm{C}$, the contact angle on vitreous carbon steadied at $36^{\circ}$ and to $38^{\circ}$ on $\mathrm{SiC}$. The virtually constant contact angle therefore considered as equilibrium contact angle at $1500^{\circ} \mathrm{C}$. 
The $\mathrm{Si}_{0.92} \mathrm{Zr}_{0.08}$ alloy showed a very different behavior under Ar compared to that under vacuum. The initial contact angle on vitreous carbon was $46^{\circ}$ at $1404^{\circ} \mathrm{C}$ and stayed almost constant for $28 \mathrm{~min}$, then suddenly dropped to $29^{\circ}$ at $1452^{\circ} \mathrm{C}$ and then stayed nearly constant throughout the experiment at $1500^{\circ} \mathrm{C}$. In contrast, $\mathrm{Si}_{0.92} \mathrm{Zr}_{0.08}$ alloy on $\mathrm{SiC}$ had an initial contact angle of $52^{\circ}$ at $1400^{\circ} \mathrm{C}$, which decreased rapidly to $46^{\circ}$ in 2 min and kept decreasing slowly to $39^{\circ}$ until the temperature reached $1500^{\circ} \mathrm{C}$ and then remained almost constant for the time of hold at that temperature. The initial, final and equilibrium contact angle for pure silicon and $\mathrm{Si} 0.92 \mathrm{Zr} 0.08$ alloy are summarized in Table 3.

Table 3 Initial, final and equilibrium contact angle of pure silicon and $\mathrm{Si}_{0.92} \mathrm{Zr}_{0.08}$ on vitreous carbon and $\mathrm{SiC}$ substrates and respective temperatures measured under an argon atmosphere.

\begin{tabular}{|c|c|c|c|c|c|}
\hline \multirow[b]{2}{*}{ Sample } & \multirow[b]{2}{*}{ Substrate } & \multirow[b]{2}{*}{$\begin{array}{c}\text { Melting } \\
\text { Temperature } \\
\left({ }^{\circ} \mathrm{C}\right)\end{array}$} & \multicolumn{3}{|c|}{ Contact angle $\left(^{\circ}\right)$} \\
\hline & & & Initial & Final & $\begin{array}{c}\text { Equilibrium } \\
\text { (at } 1500 \\
\left.{ }^{\circ} \mathrm{C}\right)\end{array}$ \\
\hline \multirow{2}{*}{ Silicon } & Vitreous carbon & 1435 & 41 & 35 & 36 \\
\hline & $\mathrm{SiC}$ & 1432 & 42 & 40 & 38 \\
\hline \multirow{2}{*}{$\mathrm{Si}_{0.92} \mathrm{Zr}_{0.08}$} & Vitreous carbon & 1404 & 46 & 44 & 29 \\
\hline & $\mathrm{SiC}$ & 1400 & 52 & 46 & 39 \\
\hline
\end{tabular}
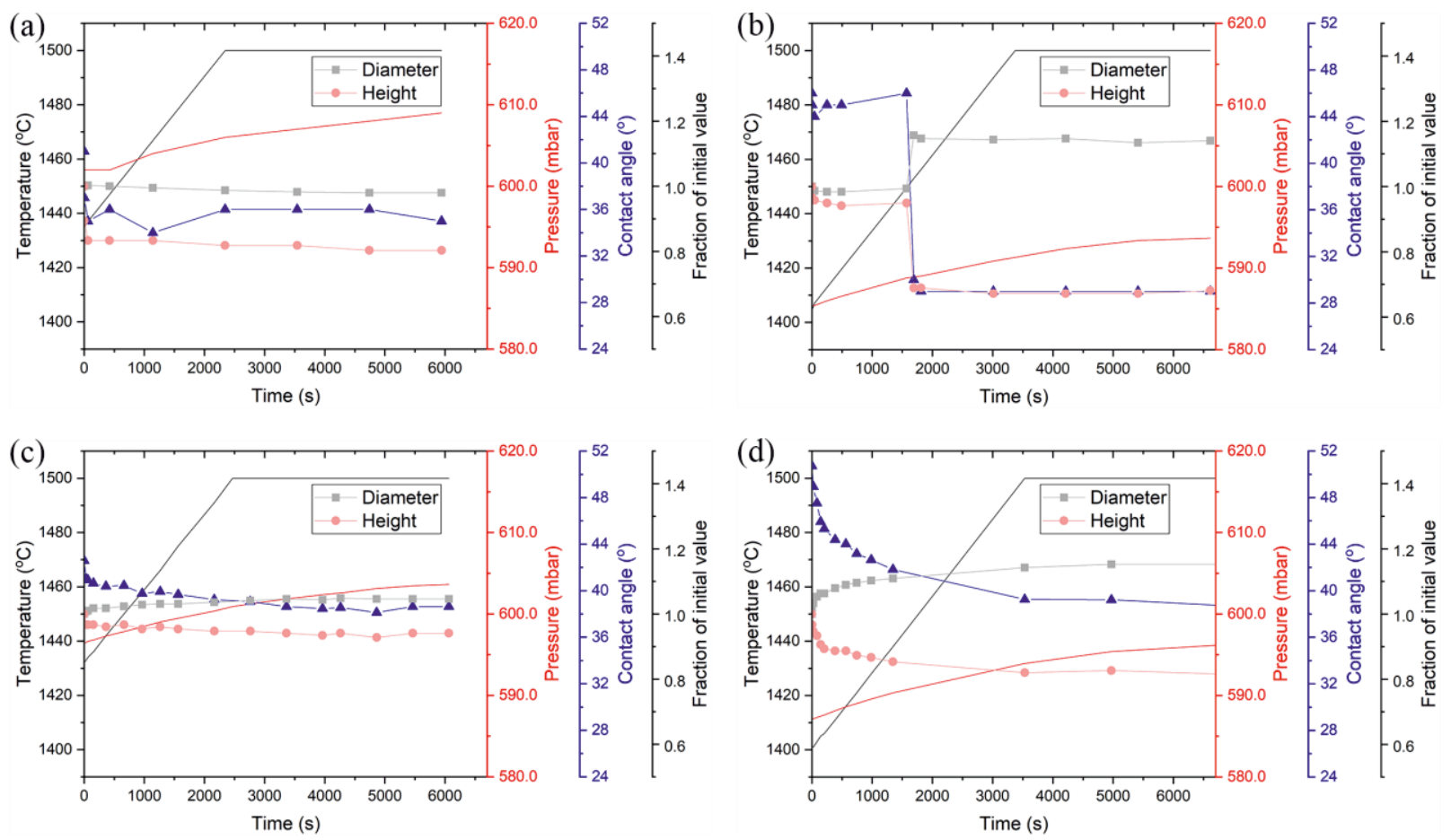

Fig. 3 Development of the contact angle, diameter and height of the droplet of (a) silicon on vitreous carbon (b) $\mathrm{Si}_{0.92} \mathrm{Zr}_{0.08}$ alloy on vitreous carbon (c) silicon on $\mathrm{SiC}$ (d) $\mathrm{Si}_{0.92} \mathrm{Zr}_{0.08}$ alloy on $\mathrm{SiC}$ with changing temperature and $\mathrm{Ar}$ pressure.

\subsection{SEM and EDX analysis}

The experimental systems can be classified into two categories, namely reactive systems, where the metal or alloy can react with the substrates to form reaction products at the interface, and non- 
reactive systems where the metal or alloy cannot react with substrates to form any reaction product. Fig. 4 (a) and (b) show the SEM images of the cross section of solidified silicon droplet on vitreous carbon. The reaction layer is composed of SiC, as analyzed by EDX (Fig. 6 (a), (b)), and has an average thickness of $\sim 5 \mu \mathrm{m}$. As for the non-reactive system, as was previously mentioned, no reaction layer appeared between pure silicon and the $\mathrm{SiC}$ substrate, as seen in Fig. 5 (a) and (b). There is, however, a slight erosion of the $\mathrm{SiC}$ substrate at the silicon and $\mathrm{SiC}$ interface.
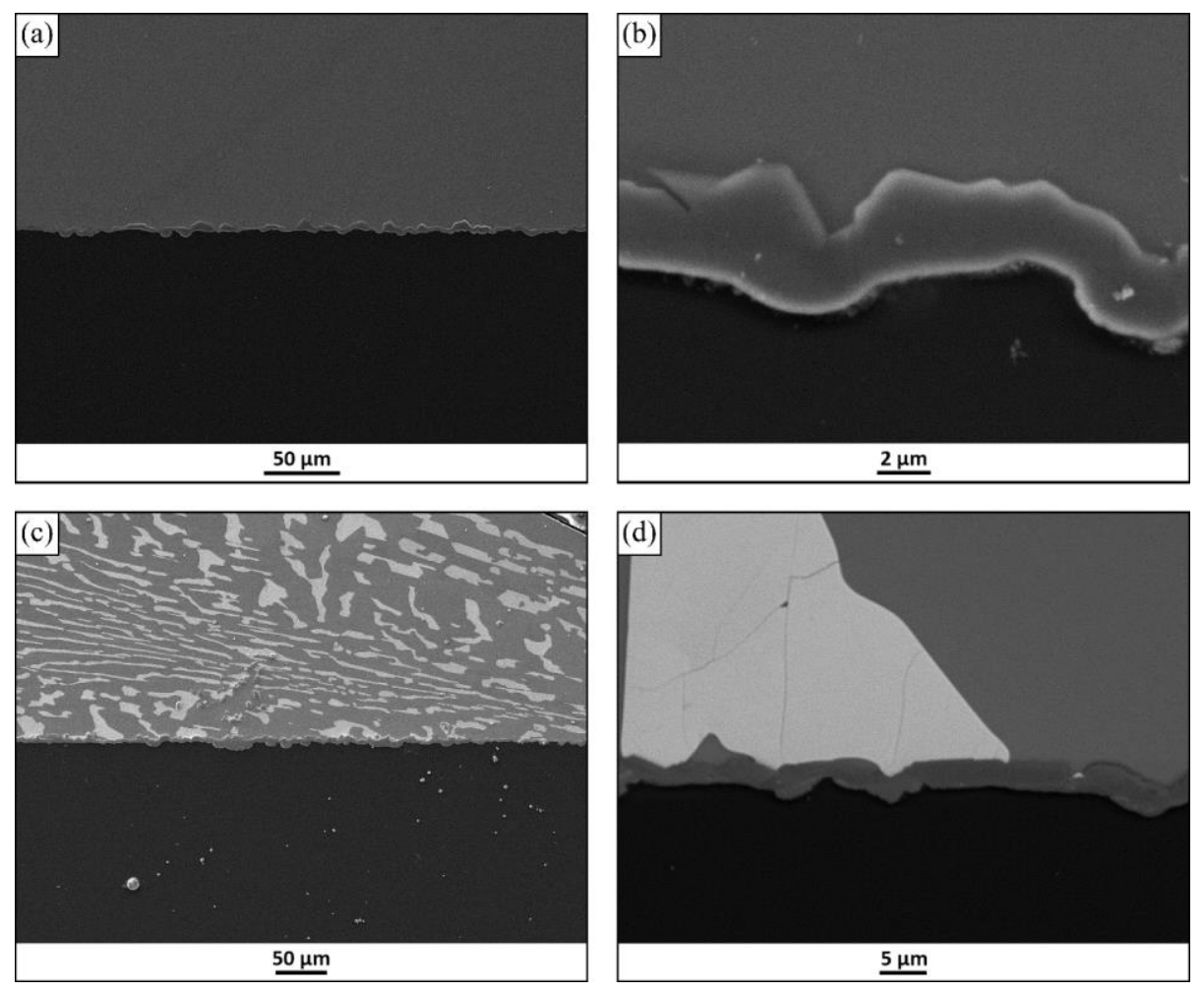

Fig. 4 SEM images of the cross section of (a), (b) the solidified silicon droplet (gray) on vitreous carbon (black) with the visible SiC reaction layer formed at the pure silicon/carbon interface, (c), (d) the solidified $\mathrm{Si}_{0.92} \mathrm{Zr}_{0.08}$ droplet on vitreous carbon (black), exhibiting needle-shaped Si-Zr phase in silicon and the SiC reaction layer formed at the interface.

The solidified droplet of the $\mathrm{Si}_{0.92} \mathrm{Zr}_{0.08}$ alloy on vitreous carbon is characterized by a typical eutectic microstructure with needle-shaped Si-Zr phase within the Si matrix (Fig. 4 (c), (d)). The reaction layer at the interface is primarily composed of $\mathrm{SiC}$ as seen by EDX analysis in Fig. 6 (c), (d). On the SiC substrate, the $\mathrm{Si} 0.92 \mathrm{Zr} 0.08$ alloy did not exhibit any continuous reaction layer (Fig. 5 (c), (d)), as was expected (Fig. 7 (c), (d)). 

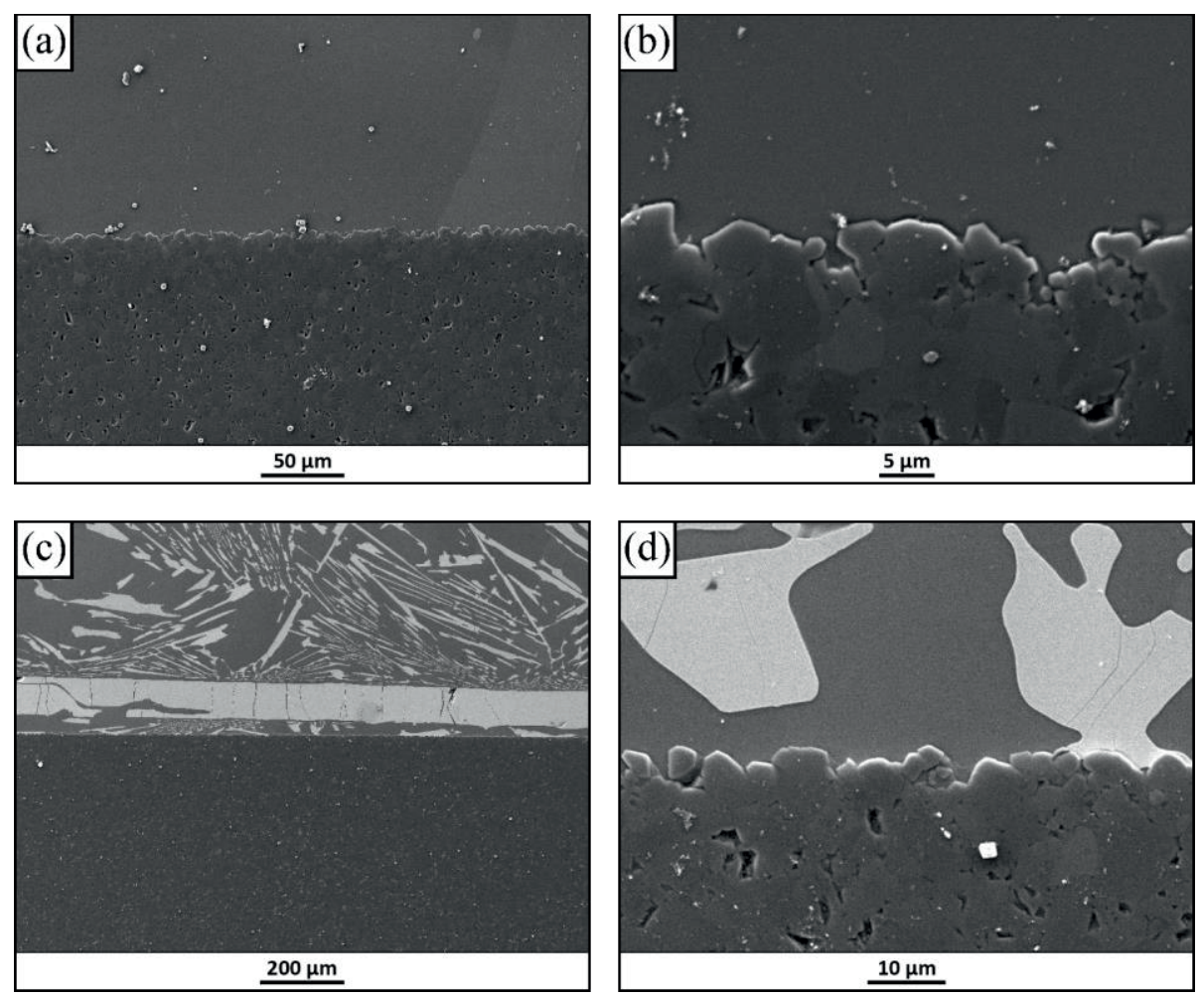

Fig. 5: SEM images of the cross section of (a), (b) solidified silicon droplet on the SiC substrate showing no reaction layer and slight erosion at interface, (c), (d) the solidified $\mathrm{Si}_{0.92} \mathrm{Zr}_{0.08}$ alloy on the SiC substrate exhibiting needle-shaped Si-Zr phase and slight erosion at the interface.
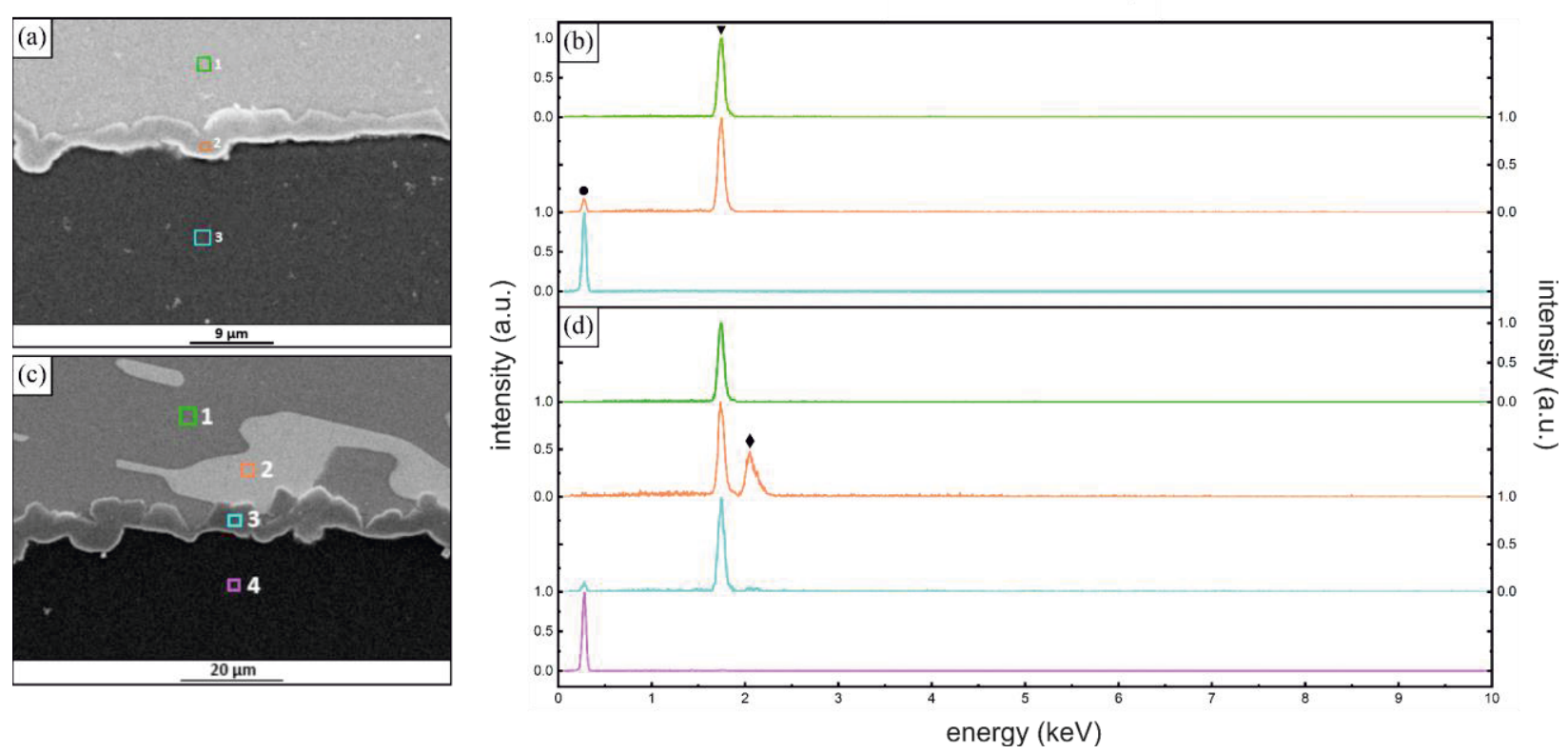

Fig. 6: EDX analysis of the interface of (a), (b) solidified silicon droplet on the vitrieous carbon substrate showing a $\mathrm{SiC}$ layer at the Si/C interface, (c), (d) solidified $\mathrm{Si}_{0.92} \mathrm{Zr}_{0.08}$ droplet on the vitreous carbon substrate showing a SiC layer at the $\mathrm{C} / \mathrm{Si}-\mathrm{Zr}$ eutectic phase interface. 
$\mathrm{C} \bullet \mathrm{Si} \nabla \mathrm{Zr} \bullet$
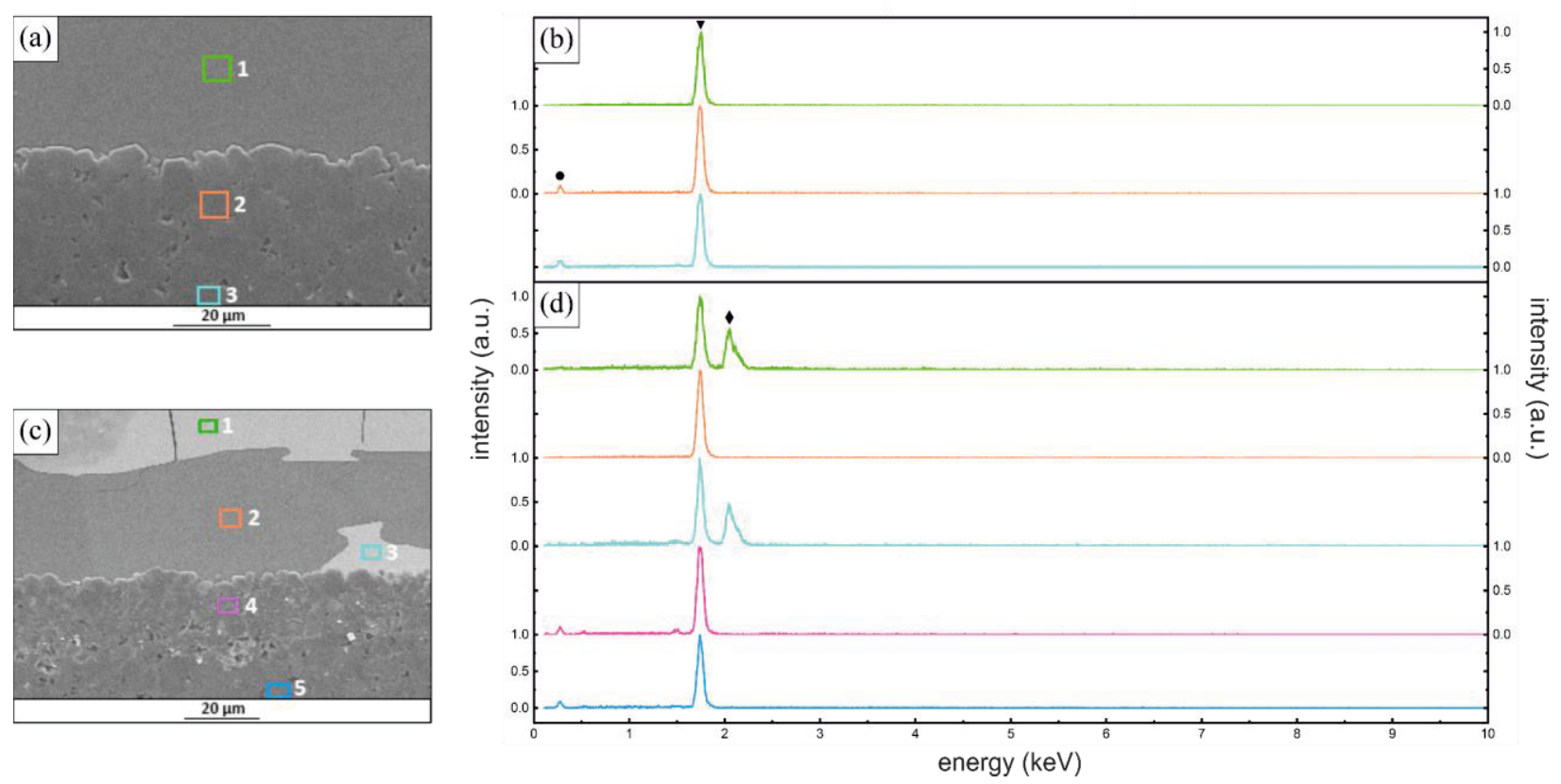

Fig. 7 EDX analysis of the interface of (a), (b) solidified silicon droplet on the SiC substrate showing no reaction layer at the Si/SiC interface, (c), (d) solidified $\mathrm{Si}_{0.92} \mathrm{Zr}_{0.08}$ droplet on the SiC substrate showing no reaction layer at the SiC/Si-Zr eutectic phase interface.

\section{Discussion}

The measurements of the contact angles of the pure silicon droplet on vitreous carbon conducted under vacuum were affected by vaporization of the liquid droplet. This resulted in an apparent decrease in the contact angle from $40^{\circ}$ to $33^{\circ}$ within $50 \mathrm{~min}$, as seen on Fig. 8 (captured at $1500^{\circ} \mathrm{C}$, 50 min interval). It was observed that the droplet's height decreased while the diameter remained constant, which is a clear indicator of liquid volume reduction. Additionally, the vacuum pressure continued to increase during the measurements, due to vaporization (Fig. 2). Nevertheless, the initial contact angle can still be considered to be a valid measurement as no significant evaporation was registered at the moment when the liquid droplet formed. It is worth mentioning that the formation of silicon vapor has significant implications during the liquid metal infiltration of porous carbon preforms. If the silicon vapors are in contact with carbon preform long time before the liquid silicon infiltration process begins, silicon vapors could infiltrate the pores and react with the carbon to form a thin layer of SiC. This may result in the formation of a diffusion barrier slowing down further conversion of carbon into $\mathrm{SiC}$ by liquid silicon.

Dezellus et. al observed the contact angle of silicon on vitreous carbon by the dispensed drop method [33]. The initial contact angle was about $150^{\circ}$ at $1430{ }^{\circ} \mathrm{C}$ which is much higher than contact angle observed in this study by using the classical sessile drop technique. There is an inherent problem with the classical sessile drop technique where the metal is melted on the substrate directly, significant part of the wetting process is absent or concealed by the melting process. Therefore the initial contact angle reported here are not corresponding to the non-reacted 
carbon substrate but rather most likely to be on reaction formed $\mathrm{SiC}$ layer during the melting process.

The melting temperature and formation of the droplet of the $\mathrm{Si}_{0.92} \mathrm{Zr}_{0.08}$ alloy occur at $30^{\circ} \mathrm{C}$ lower than that of pure $\mathrm{Si}$, which is favorable to lower the infiltration temperature. The initial slow spreading of the $\mathrm{Si}_{0.92} \mathrm{Zr}_{0.08}$ alloy droplet was observed on both the vitreous carbon and $\mathrm{SiC}$ substrates. The higher initial contact angle of the $\mathrm{Si}_{0.92} \mathrm{Zr}_{0.08}$ alloy compared to that of pure silicon may affect the infiltration kinetics adversely. The higher the contact angle, the more unfavorable the wetting becomes.
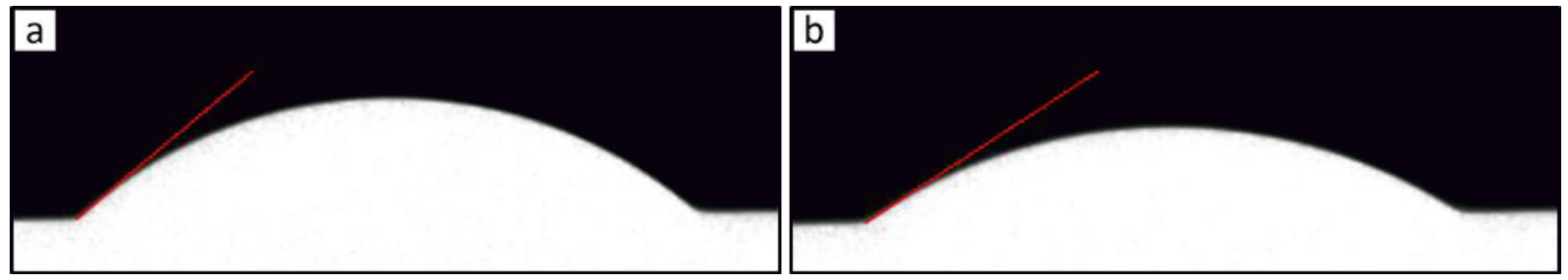

Fig. 8 Silicon droplet on vitreous carbon at $1500^{\circ} \mathrm{C}$, (a) contact angle $40^{\circ}$, (b) pseudo decrease in contact angle to $33^{\circ}$ due to evaporation.

The contact angles measured under the argon atmosphere were more reliable due to negligible evaporation of liquid droplet evident through the negligible change in the volume of the droplet with the time, measured using the height and the diameter of the droplet. The pressure in the tube remained nearly constant during the holding time. Therefore, the contact angles measured can be considered valid even after the initial contact angle as opposed to the ones measured under vacuum. However, the measurement of contact angle is very sensitive to residual oxygen in the tube, as a result of impurities in Ar. The smallest amount of oxygen could form a thin solid oxide layer, resulting in a non-spherical droplet, as seen in Fig. 9. The titanium sponge placed near the sample helped to eliminate the solid oxide film formation of the liquid sample droplet by preferential oxidation.

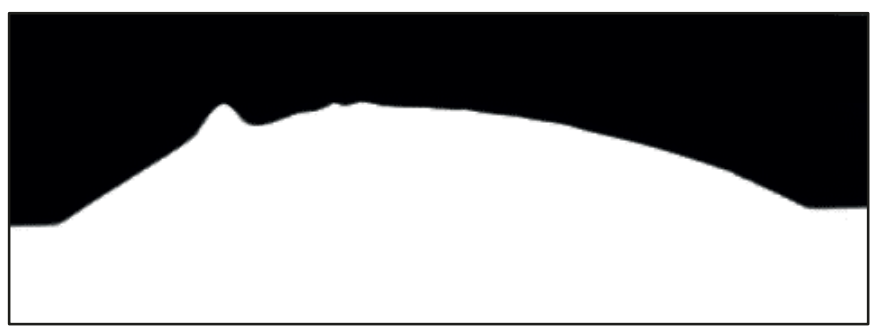

Fig. 9 Silicon droplet layer on $\mathrm{SiC}$ at $1500^{\circ} \mathrm{C}$ with a non-spherical surface due to formation of a solid oxide layer on the surface.

The contact angle showed a typical trend, i.e. that the contact angle decreased with the increase in temperature from the melting point to $1500^{\circ} \mathrm{C}$ and then reaching its equilibrium value shortly after reaching a constant temperature of $1500^{\circ} \mathrm{C}$. The measured initial contact angle of pure silicon on 
vitreous carbon and $\mathrm{SiC}$ substrates are in good agreement with previous work of Whalen et al. [23]. However, those authors did not consider the effect of evaporation due to high vacuum. Moreover, the contact angle varies significantly, depending on the type of graphite substrates, porosity and roughness [20]. The reasons for choosing the vitreous carbon substrate instead of graphite are its fully dense structure and isotropy. In some graphite substrates the liquid melt seeps through the pores by capillary forces, resulting in false contact angle measurements due to reduction in net volume of the droplet on the surface. The vitreous carbon substrates used in the experiments were fully dense preventing infiltration of silicon into porosity (Fig. 4). The Si0.92Zr0.08 alloy was characterized by a relatively slow initial droplet spreading when compared to the almost instantaneous spreading of pure $\mathrm{Si}$, where, additionally, the initial contact angle was much higher. The slower initial spreading may be caused by the homogenization process occurring during the transition from the solid eutectic phase to liquid phase or the time required for the $\mathrm{Si}$ from the $\mathrm{Si}_{0.92} \mathrm{Zr}_{0.08}$ alloy to form the $\mathrm{SiC}$ reaction layer at the interface due to lower activity of $\mathrm{Si}$ in the alloy than in the pure $\mathrm{Si}$. This could also help to explain the sudden drop of contact angle of the $\mathrm{Si} 0.92 \mathrm{Zr} 0.08$ alloy on vitreous carbon substrate from $46^{\circ}$ to $30^{\circ}$ (Fig. 3 (b)), although a more in-depth study is needed to understand this phenomenon. Even though the initial contact angle exhibits good wettability on both the vitreous carbon and $\mathrm{SiC}$ substrates, the kinetics of wetting will strongly affect the reactive infiltration process.

The SEM images showed the formation of a distinct SiC layer along both of the vitreous carbon/pure silicon and vitreous carbon/Si0.92Zr0.08 alloy interfaces (Fig. 4). The formation and growth of the $\mathrm{SiC}$ layer occurs in three stages, as explained by Voytovych et al. [22]; (i) a permeable micron thick layer of $\mathrm{SiC}$ is formed by means of nucleation and growth (ii) rapid growth of the reaction layer occurs via diffusion of carbon in liquid state silicon and a threshold layer thickness of $\sim 10 \mu \mathrm{m}$ is reached (iii) the reaction layer becomes impervious to liquid silicon, resulting in negligible growth via grain boundary diffusion of carbon where only coarsening of the reaction layer's microstructure occurs thereafter. The value of the reaction layer thickness depends on the type of carbon and its reactivity. The similarity between the contact angle of silicon on vitreous carbon and SiC substrates can be explained by the rapid formation of the solid $\mathrm{SiC}$ layer at the interface that controls the spreading. This results in further spreading of the liquid on the micron-thick SiC layer rather than directly on the vitreous carbon. Interestingly enough, the spreading on SiC substrate is slower than on the vitreous carbon. It might indeed be that the larger surface roughness of the SiC substrate slows down the triple line. Another possible explanation could have been the contamination by oxygen of $\mathrm{Si}_{0.92} \mathrm{Zr}_{0.08}$ alloy or the surface of $\mathrm{SiC}$ substrate. In long duration experiments at $1500{ }^{\circ} \mathrm{C}$, the alumina tube might act as oxygen source. However, we did not see any indication of oxide film formation on droplet which causes non uniform surface of droplet, where pieces of titanium sponge used as oxygen getter were absent (Fig. 9). Also, there is no change in contact angle during $1 \mathrm{~h}$ holding time at $1500^{\circ} \mathrm{C}$. In the case of the $\mathrm{Si} 0.92 \mathrm{Zr} 0.08$ alloy, a similar reaction layer is observed. It is however worthwhile noting that the final contact angle of the $\mathrm{Si} 0.92 \mathrm{Zr} 0.08$ alloy on the $\mathrm{SiC}$ substrate is larger than the one on vitreous carbon, albeit both contact angles 
are for the contact of the liquid with $\mathrm{SiC}$. These differences might again be caused by the difference in surface roughness between the $\mathrm{SiC}$ reaction layer and the $\mathrm{SiC}$ substrate.

The SiC substrates did not form a reaction layer at the interface with either pure silicon or the $\mathrm{Si}_{0.92} \mathrm{Zr}_{0.08}$ alloy, as seen in Fig. 5. This is in agreement with the thermodynamic assessment of $\mathrm{Si}-\mathrm{C}-\mathrm{Zr}$ system done by Chen et al. [34]. A few $\mathrm{SiC}$ grains can be seen to have become dislodged from the substrate. The surface roughness at the interface also seems to have increased when compared to the measured surface roughness $(\mathrm{Ra}=8.8-10.1 \mathrm{~nm}$ Table 1$)$ of the polished substrates before the experiment. This can be interpreted as a slight erosion of the $\mathrm{SiC}$ substrates' interface, caused by the dissolution of $\mathrm{SiC}$ in the molten droplet.

\section{Conclusion}

The contact angles measured under vacuum are affected by evaporation from the surface of the liquid droplet, resulting in a pseudo decrease in the contact angle over time. The $\mathrm{Si}_{0.92} \mathrm{Zr}_{0.08}$ alloy showed good wettability on both the vitreous carbon (equilibrium contact angle $29^{\circ}$ at $1500^{\circ} \mathrm{C}$ ) and the polycrystalline $\mathrm{SiC}$ substrates (equilibrium contact angle $39^{\circ}$ at $1500^{\circ} \mathrm{C}$ ). However, the $\mathrm{Si}_{0.92} \mathrm{Zr}_{0.08}$ alloy droplet was characterized by a higher initial contact angle and slow spreading when compared to the instantaneous spreading of the pure silicon droplet on the substrates. The formation of the continuous reaction layer of $\mathrm{SiC}$ was confirmed along both of the vitreous carbon/pure silicon and vitreous carbon/ $\mathrm{Si} 0.92 \mathrm{Zr} 0.08$ alloy interfaces. The $\mathrm{SiC}$ reaction layer growth was limited to a maximum value of $\sim 5 \mu \mathrm{m}$ in both cases, due to a newly formed $\mathrm{SiC}$ diffusion barrier layer, which prohibits the further reaction of liquid Si with the carbon substrate.

\section{Acknowledgment}

The authors are grateful to Swiss National Science Foundation (SNSF) for funding the project (Grant number 200021_163017) and the JECS Trust for funding the visit of Manoj Naikade to Institute for Nonferrous Metallurgy and Purest Materials, TU Bergakademie Freiberg, Freiberg, Germany (Contract No. 2016117).

\section{References}

[1] W. Krenkel, Cost Effective Processing of CMC Composites by Melt Infiltration (LSI-Process), 25th Annual Conference on Composites, Advanced Ceramics, Materials, and Structures: A: Ceramic Engineering and Science Proceedings, Volume 22, Issue 3, John Wiley \& Sons, Inc.2001, pp. 443-454.

[2] J.C. Margiotta, D.J. Zhang, D.C. Nagle, Microstructural evolution during silicon carbide (SiC) formation by liquid silicon infiltration using optical microscopy, Int J Refract Met H 28(2) (2010) 191-197.

[3] O.P. Chakrabarti, P.K. Das, High temperature load-deflection behaviour of reaction bonded SiC (RBSC), Ceramics International 27(5) (2001) 559-563.

[4] G.S. Corman, K.L. Luthra, Silicon Melt Infiltrated Ceramic Composites (HiPerComp ${ }^{\mathrm{TM}}$ ), in: N.P. Bansal (Ed.), Handbook of Ceramic Composites, Springer US, Boston, MA, 2005, pp. 99-115.

[5] A.A. Galiguzov, A.M. Kenigfest, A.P. Malakho, A.N. Seleznev, V.V. Avdeev, Study of process of erosion of various types of carbon fibres by molten silicon, Fibre Chem+44(2) (2012) 101-105.

[6] P. Sangsuwan, J.A. Orejas, J.E. Gatica, S.N. Tewari, M. Singh, Reaction-bonded silicon carbide by reactive infiltration, Ind Eng Chem Res 40(23) (2001) 5191-5198. 
[7] M.H. Hon, R.F. Davis, Self-diffusion of14C in polycrystalline $\beta$-SiC, Journal of Materials Science 14(10) (1979) 2411-2421.

[8] P. Eveno, J. Li, A.M. Huntz, J. Chaumont, Diffusion of C-13 and Si-29 Implanted Ions in Sic, Mat Sci Eng B-Solid 11(1-4) (1992) 331-336.

[9] J.F. White, L. Ma, K. Forwald, D. Sichen, Reactions Between Silicon and Graphite Substrates at High Temperature: In Situ Observations, Metallurgical and Materials Transactions B 45(1) (2013) 150-160.

[10] V. Bougiouri, R. Voytovych, N. Rojo-Calderon, J. Narciso, N. Eustathopoulos, The role of the chemical reaction in the infiltration of porous carbon by NiSi alloys, Scripta Materialia 54(11) (2006) 1875-1878.

[11] R. Voytovych, V. Bougiouri, N.R. Calderon, J. Narciso, N. Eustathopoulos, Reactive infiltration of porous graphite by NiSi alloys, Acta Materialia 56(10) (2008) 2237-2246.

[12] Y.G. Tong, S.X. Bai, K. Chen, C/C-ZrC composite prepared by chemical vapor infiltration combined with alloyed reactive melt infiltration, Ceramics International 38(7) (2012) 5723-5730.

[13] R.P. Messner, Y.-M. Chiang, Liquid-Phase Reaction-Bonding of Silicon Carbide Using Alloyed SiliconMolybdenum Melts, Journal of the American Ceramic Society 73(5) (1990) 1193-1200.

[14] Y.M. Chiang, R.P. Messner, Method of preparing refractory silicon carbide composites and coatings, Massachusetts Institute Of Technology, Patent number US5079195 A (1992)

[15] S. Meier, J.G. Heinrich, Processing-microstructure-properties relationships of MoSi2-SiC composites, Journal of the European Ceramic Society 22(13) (2002) 2357-2363.

[16] Y.G. Wang, X.J. Zhu, L.T. Zhang, L.F. Cheng, C/C-SiC-ZrC composites fabricated by reactive melt infiltration with Si0.87Zr0.13 alloy, Ceramics International 38(5) (2012) 4337-4343.

[17] H. Li, L. Zhang, L. Cheng, Y. Wang, Fabrication of 2D C/ZrC-SiC composite and its structural evolution under high-temperature treatment up to $1800^{\circ} \mathrm{C}$, Ceramics International 35(7) (2009) 2831-2836.

[18] N.R. Calderon, R. Voytovych, J. Narciso, N. Eustathopoulos, Wetting dynamics versus interfacial reactivity of AISi alloys on carbon, Journal of Materials Science 45(8) (2009) 2150-2156.

[19] H. Pi, S. Fan, Y. Wang, C/SiC-ZrB2-ZrC composites fabricated by reactive melt infiltration with ZrSi2 alloy, Ceramics International 38(8) (2012) 6541-6548.

[20] A. Ciftja, T.A. Engh, M. Tangstad, Wetting Properties of Molten Silicon with Graphite Materials, Metallurgical and Materials Transactions A 41(12) (2010) 3183-3195.

[21] J.-G. Li, H. Hausner, Wetting and infiltration of graphite materials by molten silicon, Scripta Metall Mater 32(3) (1995) 377-382.

[22] R. Voytovych, R. Israel, N. Calderon, F. Hodaj, N. Eustathopoulos, Reactivity between liquid Si or Si alloys and graphite, Journal of the European Ceramic Society 32(14) (2012) 3825-3835.

[23] T.J. Whalen, A.T. Anderson, Wetting of SiC, Si3N4, and Carbon by Si and Binary Si Alloys, Journal of the American Ceramic Society 58(9-10) (1975) 396-399.

[24] Z. Yuan, W.L. Huang, K. Mukai, Wettability and reactivity of molten silicon with various substrates, Applied Physics A: Materials Science \& Processing 78(4) (2004) 617-622.

[25] K. Landry, C. Rado, R. Voitovich, N. Eustathopoulos, Mechanisms of reactive wetting: The question of triple line configuration, Acta Materialia 45(7) (1997) 3079-3085.

[26] K. Landry, C. Rado, N. Eustathopoulos, Influence of interfacial reaction rates on the wetting driving force in metal/ceramic systems, Metallurgical and Materials Transactions A 27(10) (1996) 3181-3186.

[27] V. Bougiouri, R. Voytovych, O. Dezellus, N. Eustathopoulos, Wetting and reactivity in Ni-Si/C system: experiments versus model predictions, Journal of Materials Science 42(6) (2007) 2016-2023.

[28] B. Drevet, N. Eustathopoulos, Wetting of ceramics by molten silicon and silicon alloys: a review, Journal of Materials Science 47(24) (2012) 8247-8260.

[29] R. Israel, R. Voytovych, P. Protsenko, B. Drevet, D. Camel, N. Eustathopoulos, Capillary interactions between molten silicon and porous graphite, Journal of Materials Science 45(8) (2010) 2210-2217.

[30] G.W. Liu, M.L. Muolo, F. Valenza, A. Passerone, Survey on wetting of SiC by molten metals, Ceramics International 36(4) (2010) 1177-1188. 
[31] P.J. Yunes Rubio, L. Hong, N. Saha-Chaudhury, R. Bush, V. Sahajwalla, Dynamic Wetting of Graphite and $\mathrm{SiC}$ by Ferrosilicon Alloys and Silicon at $1550^{\circ} \mathrm{C}$, ISIJ International 46(11) (2006) 1570-1576.

[32] J. Roger, A. Marchais, Y. Le Petitcorps, Examination of the interaction between liquid silicon and bulk silicon carbide, J Cryst Growth 426 (2015) 1-8.

[33] O. Dezellus, S. Jacques, F. Hodaj, N. Eustathopoulos, Wetting and infiltration of carbon by liquid silicon, Journal of Materials Science 40(9-10) (2005) 2307-2311.

[34] H.M. Chen, Y. Xiang, S. Wang, F. Zheng, L.B. Liu, Z.P. Jin, Thermodynamic assessment of the C-Si-Zr system, Journal of Alloys and Compounds 474(1-2) (2009) 76-80. 